\title{
Can antidepressants unlock prescription of rimonabant in the fight against COVID-19?
}

(c) The Author(s), under exclusive licence to Springer Nature Limited 2021

Molecular Psychiatry (2021) 26:7091-7092; https://doi.org/10.1038/s41380-021-01221-y

\section{TO THE EDITOR:}

We read with real enthusiasm the paper by Hoertel et al. [1] showing an "association between antidepressant use and reduced risk of intubation or death in hospitalized patients with COVID-19". Their observation reinforces preliminary data of a double-blind, randomized clinical trial showing significant reduction of COVID-19 worsening in outpatients treated with fluvoxamine [2]. By the time those promising results should obviously stimulate organization of large randomized clinical trials on the use of antidepressants in the fight against COVID-19, we want to plead for introducing rimonabant combined to an antidepressant in some of those trials as well as in preclinical studies.

We recently proposed to use rimonabant in order to prevent severity of SARS-Cov-2 infection observed in patients with obesity [3]. Our suggestion to reposition this inverse agonist of CB1 cannabinoid receptor (CB1R) rested on the ability of rimonabant to decrease not only metabolic parameters but also chronic inflammatory state of macrophage-infiltrated adipose tissue, which might contribute to the cytokine storm appearing in the end stages of lethal COVID-19. Rimonabant exerts its anti-obesity effects by acting on central CB1R, thus reducing food intake, as well as on peripheral CB1R present in adipose tissue, liver, intestine, and muscle. As recalled in our Perspective paper [3], inhibition of central CB1R also leads to serious psychiatric secondary events, mainly a tendency to depression leading in some cases to suicide. For those reasons rimonabant, which was never approved by US Food and Drug Administration, was withdrawn from European market in 2008. Second- and third-generation CB1 antagonists unable to cross the blood-brain barrier might have been used instead [3], as also recently suggested by Cinar et al. [4], however, none of them are sufficiently engaged in clinical trials to meet urgent need created by the outbreak, even with vaccines being now available [3]. Therefore, discovering in the literature the properties of antidepressants mentioned above $[1,2]$ gave birth to the very simple idea to combine rimonabant with an antidepressant in order to avoid deleterious effects of the former under conditions susceptible to reveal additive or synergistic effects of the two types of drugs on the outcome of COVID-19.

Beside the fact that antidepressants, like rimonabant, are associated with decreased plasma levels of various cytokines (IL-10, TNF-a, CCL-2, and IL-6) [1], the combination of the two drugs involves two different targets, since antidepressants are thought to impair SARS-Cov-2 entry into epithelial cells by functional inhibition of acid sphingomyelinase (ASmase) [5, 6]. Relevance of this mechanism was recently confirmed by the observation that other ASmase functional inhibitors (antihistamines, antipsychotics, calcium channel blockers, mucolytics) also protect from severe forms of COVID-19 [7]. However, a close relationship between sphingomyelin metabolism and CB1R was recently reported in a study showing that sphingomyelin accumulation subsequent to ASmase deficiency promoted disappearance of membrane CB1R through internalization and lysosomal degradation [8]. On the other hand, chronic activation of CB1R (induced by inhibiting enzymatic degradation of the CB1R ligand anandamide) dampened sphingomyelin excessive storage in ASmase-knock-out mice [8]. Since inhibition of ASmase results in some accumulation of sphingomyelin [6], such a crosstalk between the two metabolisms (sphingomyelin-ceramide and endocannabinoids, respectively) could cast some doubts about the advantage of combining rimonabant with an antidepressant. However, sphingomyelin accumulation in hippocampal Golgi or endoplasmic reticulum fractions of mice treated with amitriptyline remained 7- to 11-fold lower, respectively, than the massive increase observed in ASmasedeficient mice [8]. To the best of our knowledge, there is no report that antidepressants could induce the dramatic changes observed in ASmase deficiency characterizing Niemann-Pick disease type $A$.

Among available literature data on rimonabant coupled to antidepressants, one study explored the ability of the former to reduce undesirable weight gain induced by chronic treatment with desipramine in mouse [9]. At 20 days following the onset of treatment, the antidepressant effect of desipramine was not altered by rimonabant. Moreover, no obvious unsuited event was observed, except for a transient tendency to anxiety-like behavior, whose mechanism remains unclear. This 3-weeks period is important to consider in the light of the fact that the duration of rimonabant plus antidepressant treatment of COVID-19 patients would be of the same order of magnitude.

Finally, comparison of two trials conducted with rimonabant clearly indicated that the risk of serious psychiatric events is significantly reduced when restricting anti-obesity treatment to patients presenting with no history of depression $[10,11]$.

Starting from the presently available evidence, three possibilities could be considered: (1) develop preclinical studies with third-generation CB1 antagonists, but this would then require time-consuming phase 1 and 2 trials; (2) undergo preclinical studies using rimonabant plus an antidepressant, in order to confirm or invalidate our proposal, but again the advantage of repurposing both types of drugs, which all have gone through phase 3 and 4 trials, would move away from the urgent need created by the ongoing pandemic; (3) start as soon as possible clinical trials with high-risk patients admitted to hospital following SARS-Cov2 infection and presenting a body max index $\geq 30 \mathrm{~kg} / \mathrm{m}^{2}$. Treatment could involve coupling of fluoxetine at the dose used in the previous retrospective study, i.e., $20 \mathrm{mg} /$ day [1], to the dose of rimonabant previously shown to be efficient at reducing body 
weight $(20 \mathrm{mg} /$ day) for a duration covering all the time spent in the hospital, i.e., between 2 and 4 weeks. Importantly, trial should not include patients with a history of depression and appropriate psychiatric surveillance should be maintained several weeks after discharge from hospital.

Juliette Salles $^{1,2}$, Fabienne Briand-Mésange ${ }^{1}$, Stéphanie Trudel ${ }^{1,3}$ Jérôme Ausseil ${ }^{1,3}$, Jean-Pierre Salles (iD) ${ }^{1,4}$ and Hugues Chap (iD ${ }^{1 凶}$ ${ }^{1}$ Infinity (Toulouse Institute for Infectious and Inflammatory Diseases), INSERM UMR1291, CNRS UMR5051, Université Toulouse III, Toulouse, France. ${ }^{2} \mathrm{CHU}$ de Toulouse, Service de psychiatrie et psychologie, psychiatrie, Toulouse, France. ${ }^{3} \mathrm{CHU}$ Toulouse, Institut Fédératif de Biologie, Laboratoire de Biochimie, Toulouse, France.

${ }^{4} \mathrm{CHU}$ de Toulouse, Centre de référence du Syndrome de Prader-Willi et autres syndromes avec troubles du comportement alimentaire, Unité d'endocrinologie, obésités, maladies osseuses, génétique et gynécologie médicale, Toulouse, France. 凶email: hugues.chap@inserm.fr

\section{REFERENCES}

1. Hoertel N, Sánchez-Rico M, Vernet R, Beeker N, Jannot AS, Neuraz A, et al. Association between antidepressant use and reduced risk of intubation or death in hospitalized patients with COVID-19: results from an observational study. Mol Psychiatry. 2021. https://doi.org/10.1038/s41380-021-01021-4.

2. Lenze EJ, Mattar C, Zorumski CF, Stevens A, Schweiger J, Nicol GE, et al. Fluvoxamine vs placebo and clinical deterioration in outpatients with symptomatic COVID-19: a randomized clinical trial. JAMA. 2020;324:2292-2300.

3. Briand-Mésange F, Trudel S, Salles J, Ausseil J, Salles JP, Chap H. Possible role of adipose tissue and the endocannabinoid system in coronavirus disease 2019 pathogenesis: can rimonabant return? Obesity. 2020;28:1580-1.

4. Cinar R, lyer MR, Kunos G. Dual inhibition of CB1 receptors and iNOS, as a potential novel approach to the pharmacological management of acute and long COVID-19. Br J Pharmacol. 2021. https://doi.org/10.1111/bph.15461.

5. Carpinteiro A, Edwards MJ, Hoffmann M, Kochs G, Gripp B, Weigang S, et al. Pharmacological inhibition of acid sphingomyelinase prevents uptake of SARSCoV-2 by epithelial cells. Cell Rep Med. 2020;1:100142.
6. Gulbins A, Schumacher F, Becker KA, Wilker B, Soddemann M, Boldrin F, et al. Antidepressants act by inducing autophagy controlled by sphingomyelin-ceramide. Mol Psychiatry. 2018;23:2324-46.

7. Hoertel N, Sánchez-Rico M, Gulbins E, Kornhuber J, Carpinteiro A, Lenze EJ, et al. Association between FIASMAs and reduced risk of intubation or death in individuals hospitalized for severe COVID-19: an observational multicenter study. Clin Pharmacol Ther. 2021. https://doi.org/10.1002/cpt.2317.

8. Bartoll A, Toledano-Zaragoza A, Casas J, Guzmán M, Schuchman EH, Ledesma MD. Inhibition of fatty acid amide hydrolase prevents pathology in neurovisceral acid sphingomyelinase deficiency by rescuing defective endocannabinoid signaling. EMBO Mol Med. 2020;12:e11776.

9. Gobshtis N, Ben-Shabat S, Fride E. Antidepressant-induced undesirable weight gain: prevention with rimonabant without interference with behavioral effectiveness. Eur J Pharm. 2007;554:155-63.

10. Nissen $S E$, Nicholls SJ, Wolski K, Rodés-Cabau J, Cannon CP, Deanfield JE, et al. Effect of rimonabant on progression of atherosclerosis in patients with abdominal obesity and coronary artery disease: the STRADIVARIUS randomized controlled trial. JAMA. 2008;299:1547-60.

11. Després JP, Ross R, Boka G, Alméras N, Lemieux I, ADAGIO-Lipids Investigators. Effect of rimonabant on the high-triglyceride/ low-HDL-cholesterol dyslipidemia, intraabdominal adiposity, and liver fat: the ADAGIO-Lipids trial. Arterioscler Thromb Vasc Biol. 2009;29:416-23.

\section{COMPETING INTERESTS}

The authors declare no competing interests.

\section{ADDITIONAL INFORMATION}

Correspondence and requests for materials should be addressed to H.C.

Reprints and permission information is available at http://www.nature.com/ reprints

Publisher's note Springer Nature remains neutral with regard to jurisdictional claims in published maps and institutional affiliations. 